\title{
Influence of Different Counting Parameters for the Measurement of Thyroid and Thyroid Related Hormones Using Radio Immuno Assay (RIA) Technique and ${ }^{125}$ I Isotopes
}

\author{
Md Anwarul Kabir Bhuiya ${ }^{1 *}$, Raihana Ferdaws ${ }^{1}$, Abu Mahmud ${ }^{1}$, Md Abdul Halim ${ }^{1}$, Md Shahnewaz Parvez ${ }^{1}$, \\ Shefali Khatun², Nasrin Laz ${ }^{2}$ and Md Shariful Islam Chowdhury ${ }^{2}$ \\ ${ }^{1}$ Department of Materials Science and Engineering, University of Rajshahi, Rajshahi, Bangladesh \\ ${ }^{2}$ Institute of Nuclear Medicine and Allied Sciences (INMAS), BAEC, Rajshahi, Bangladesh
}

*Corresponding author: Md Anwarul Kabir Bhuiya, Department of Materials Science

Received Date: March 10, 2019

and Engineering, University of Rajshahi, Rajshahi, Bangladesh.

Published Date: May 07, 2019

\begin{abstract}
Different methods for the determination of thyroid and related hormone have been reviewed. Performance characteristics of the radio isotopic method for the hormone assay were identified. Bound $\mathrm{T}_{3}$, Bound $\mathrm{T}_{4}, \mathrm{TSH}$ and Free $\mathrm{T}_{4}$ were assayed using different counting time and two different pulse height window levels. A very little difference was found during the measurement. The whole procedure was performed using Canberra AccuSpec NaI system, which has a high precision and stability. (c Squire equals to 3.56, detector resolution 9.10\% and a $2 \mathrm{k}$ channel MCA). It is noticed that for low counting measurement counting time and window effect are present. It is assumed that for analog devices with single channel system the difference may be significant.
\end{abstract}

Keywords: Radio Immuno Assay (RIA), Counting time; Window levels; Radioactive Materials; Gamma Camera; Thyroid Hormones

\section{Introduction}

Hormones are the organic substances, which are secreted by the ductless glands (endocrine glands). They are brought to the different organs of the body by means of blood stream, to produce the various physiological functions. The deficiency of a hormone leads to a particular disease (pathological condition). Radio isotopic method for the determination of hormone level in human blood serum is a unique way in comparison to other methods. The concentration of the hormone molecules has a wide range from Nano mole per liter to low concentration like Pico mol per liter. Signal to noise ratio is not high enough in some cases like $T_{3}, T_{4}$, and TSH in hyperthyroid cases where presence of activity is very low. Standard counting time for each tube is one minute. But due to very large number of assay tubes sometimes end users reduce the counting time to 30 seconds. As the counting time decreases, the count rate decreases per tube. As a result, signal to noise ratio falls significantly. One way to compensate for the count rate is to increase the counting time for each tube but the problem is that it requires more time to analyze the sample. In a busy department, it is not possible to spare a long spell of time for each batch [1-3].

\section{Experimental}

\section{Materials}

${ }^{125}$ I is a widely used radionuclide with a half-life of 59.4 days. It emits x-rays with a maximum energy of $35 \mathrm{keV}$. It is produced by irradiating Xenon-124 to create Xenon-125, which then decays to form ${ }^{125} \mathrm{I}$.

We have significant experience in the operation and production of ${ }^{125}$ I in a closed loop system. Our unique closed loop system eliminates the need for a decay period for Iodine-126 ensuring that you get the freshest and highest purity ${ }^{125} \mathrm{I}$ possible accompanied by NIST traceable activity certifications [4-8].

${ }^{125}$ I is used in radioimmunoassay to label antibodies, single stranded or double stranded DNA fragments, oligonucleotides, RNA as well as proteins and peptides. Radioimmunoassay is used in biomedical research as well as in clinical tests including diagnosing thyroid disorders [9-11].

${ }^{125}$ I is also used in tracer drugs for diagnostic imaging. Applications include detecting glomerular filtration rate (GFR), 
mapping of receptors in the brain, and use as a sealed source in osteoporosis detection [12-14].

\section{Methods}

Radioimmunoassay method for the determination of hormone level in human blood serum is a unique way in comparison to other methods. Serum $\mathrm{T}_{4}, \mathrm{~T}_{3}$ and TSH were measured using RIA kits. To measure levels of $\mathrm{T}_{3}, \mathrm{~T}_{4}$ and TSH known amount of radioactively labeled antigen mixed with fixed amount of specific antibody and anti-immunoglobulin antibodies. The radioactivity was measured from the precipitation. To measure levels of $\mathrm{T}_{3}, \mathrm{~T}_{4}$ and TSH known amount of radioactively labeled antigen mixed with unknown amount of unlabeled antigen and fixed amount of specific antibody $[4,5]$.

Signal to noise ratio is not high enough in some cases like $\mathrm{T}_{3}, \mathrm{~T}_{4^{\prime}}$ and TSH in hyperthyroid cases where presence of activity is very low. Standard counting time for each tube is one minute. However, due to very large number of assay tubes sometimes end users reduce the counting time to 30 seconds. As the counting time decreases, the count rate decreases per tube. As a result, signal to noise ratio falls significantly. One way to compensate for the count rate is to increase the counting time for each tube but the problem is that it requires more time to analyze the sample. In a busy department, it is not possible to spare a long spell of time for each batch.

The radioimmunoassay method depends on the competition between ${ }^{125}$-labelled $\mathrm{T}_{3}$ and $\mathrm{T}_{3}$ contained in standards or in specimens to be assayed, for a fixed and limited number of $\mathrm{T}_{3}$ antibody binding sites. After the incubation, the amount of ${ }^{125}$ I-labelled $\mathrm{T}_{3}$ bound to the antibody is inversely related to the amount of $\mathrm{T}_{3}$ present in the sample. By measuring the proportion of ${ }^{125} \mathrm{I}$-labelled $\mathrm{T}_{3}$ bound in the presence of reference standards containing various known amounts of $\mathrm{T}_{3}$, the concentration of present in unknown samples can be interpolated [10,11].

\section{Contents of supplied kit:}

- 4 vials $(148 \mathrm{kBq})^{125} \mathrm{I}_{-} \mathrm{T}_{3}$ solution $(4 \times 21 \mathrm{ml}, \mathrm{red})$

- 2 vials $\mathrm{T}_{3}$ antibody $(2 \times 21 \mathrm{ml}$, blue $)$,

- $\mathrm{T}_{3}$ standards $(2 \times 6$ vials $) .1 \mathrm{ml}$ distilled water should pipette into zero standard. $0.5 \mathrm{ml}$ distilled water should pipette into each of the other vials of $\mathrm{T}_{3}$ standards for reconstitution and should stand for 5 minutes. The concentrations are $0.5,1.0,2.0,4.0,8.0 \mathrm{ng} / \mathrm{ml}$.

- 4 vials PR B, before used the reagents should be thoroughly mixed by gentle shaking and swirling to ensure a homogeneous suspension.

\section{List of required equipment and materials:}

- Disposable polystyrene tubes

- Micropipettes with disposable tips (50, 100, 200 and $500 \mu \mathrm{l}$ )

- Vortex type mixer

- Multisampling centrifuge (greater than 1500g)
- $\quad$ Tube rack

- Water bath at $37^{\circ} \mathrm{C}$

- Gamma counter

\section{Experimental procedure of assay:}

- The order of the steps should be followed exactly.

- Assay tubes should label and arrange in the assay rack.

- $\quad 50 \mu \mathrm{l}$ aliquots of the standards or samples should pipette into the prelabelled tubes (see Table 1).

- $\quad 200 \mu \mathrm{l}^{125} \mathrm{I}_{-} \mathrm{T}_{3}$ solution (red) should dispense into each tube.

- $\quad 100 \mu \mathrm{l} \mathrm{T}$ antibody should dispense to each tube (expect “T”).

- The tubes should vortex thoroughly and incubate at $37{ }^{\circ} \mathrm{C}$ for 60 minutes.

- $\quad 500 \mu \mathrm{l}$ precipitant should dispense into each tube expect "T".

- $\quad$ The tubes should centrifuge for 20 minutes at $1500 \times \mathrm{g}$.

- The supernatant should discard by decantation or suction (expect 'T").

- All the tubes should count in a suitable gamma counter.

\section{Synthesis of thyroid hormones and secretion}

Thyroid hormone is synthesized in the thyroid gland by a complex mechanism. Although the precursor for both $\mathrm{T}_{4}$ and $\mathrm{T}_{3}$ is tyrosine, the synthesis does not occur on the free amino acid but rather on the tyrosine residues of the large protein thyroglobulin. The thyroglobulin is synthesizing by the cells of the thyroid gland and stored in a follicle surrounded by glandular cells.

The first step in the synthesis of thyroid hormone is the accumulation of iodine. This is an active process requiring energy and concentration iodine up to 10,000-fold over serum. Although the details are not complete, the iodine mechanism apparently is linked to a $\mathrm{Na}^{+} / \mathrm{K}^{+}-$ATPase. Drugs that block the ATPase, such as ouabain destroy the thyroid's ability to concentrate iodine. The concentration mechanism can also be inhibited by a variety of large in organic anions such as perchlorate and thiocyanate. Thus, patients with a dietary excess of rut a base, which contains large amounts of thiocyanate may be hyperthyroid because of a lack of intracellular iodine [6].

The next step in the thyroid hormone synthesis involves the ramification of the iodine. The diet of this is not clear, but electron microscopic evidence indicates that it occurs at the apical plasma membrane or within the storage follicle itself. The iodine concentrated by the gland is in the form of iodine ions. This iodide reacts with hydrogen per-oxide and tyrosine residues on thyroglobulin to form mono iodothyronines (MITS) within the thyroglobulin [7]. 
The last step in the formation of the thyroid hormone is the coupling of iodothyronines to form tyrannies. Coupling occurs by the translation of the iodophenolic ring from one iodotyrosine to the phenol group of another resulting in the formation of a thyroxin and serine. The coupling of two Dits yields a $\mathrm{T}_{4}$ and the coupling of MITS to a DIT $\mathrm{T}_{3}$ MIT $\mathrm{s}$ are usually not coupling together this would result in an inactive compound.

Under usual condition, almost all thyroid hormone production by the thyroid is $\mathrm{T}_{4}(90 \%)$. The thyroglobulin which may condition up to eight thyroxin molecules is stored as colloid. It is pinocytosed by the cells and proteolytically degraded, releasing the $\mathrm{T}_{4}$ the $\mathrm{T}_{3}$. The thyroid cells salvage the iodine from the MIT and DIT reuses it. An inability to salvage iodine from the iodotyrosines, although very rare leads to iodine deficiency and hypothyroidism.

Almost all $\mathrm{T}_{3}$ is not synthesize by the thyroid gland but rather is formed by removal of iodine from the outer ring of $\mathrm{T}_{4}$ in other tissues. Many of these tissues also have the ability to remove an inactive compound found in large amount in-patients with chronic disease. This unusual deiodination dose not lead to thyroid disease, but it does confuse the physician because the thyroid test may show an abnormality in the $\mathrm{T}_{3}$ level. Patients with it are called euthyroid sick.

\section{Results and Discussion}

$\mathbf{T}_{3}$

The normal range of $\mathrm{T}_{3}$ hormone in a human serum is 1.34 to 3.34 $\mathrm{nmol} / \mathrm{l}$. In calculation, the count rate decreases with the increases of concentration of $\mathrm{T}_{3}$ molecule present in the serum. Therefore, with low concentration, high-count rate is available and the signal to noise ratio is high. As a result, for a hypothyroid patient sufficient count is available. From the data it is observed that counting time do not play a significant role. Errors generated are not significant. However, for higher concentration of $\mathrm{T}_{3}$ molecule the available count rate is very low in comparison to background count. So high level of errors may generate in the result, high counting time may be helpful to reduce the statistical errors.

$\mathbf{T}_{4}$

The normal range is $54 \mathrm{nmol} / \mathrm{l}$ to $174 \mathrm{nmol} / \mathrm{l}$. In calculation, the count rate also decreases with the increases of concentration like $\mathrm{T}_{3}$ molecule present in the serum. Therefore, with low concentration, high-count rate is available and the signal to noise ratio is high. As a result, for a hypothyroid patient sufficient count is available. From the data it is observed that counting time do not play a significant role. Errors generated are not significant. However, for higher concentration of $\mathrm{T}_{4}$ molecule, the available count rate is very low in comparison to background count. So high level of errors may generate in the result, high counting time may be helpful to reduce the statistical errors.

\section{TSH}

Normal range of the TSH hormone in the human body is 0.50 to $5.00 \mathrm{nmol} / \mathrm{l}$ of plasma. It is measured using IRMA method containing magnetic material and is separated with strong magnetic field. Unlike $\mathrm{T}_{3}$ and $\mathrm{T}_{4}$, the count increases with the increase of concentration of the serum. From the data, it is seen that higher concentration error is less (about $\pm 1 \%$ ) but with low count as in hyper cases, error is about $( \pm 2.5 \%$ ) (Tables $1-3$ \& Figures $1-3$ ).

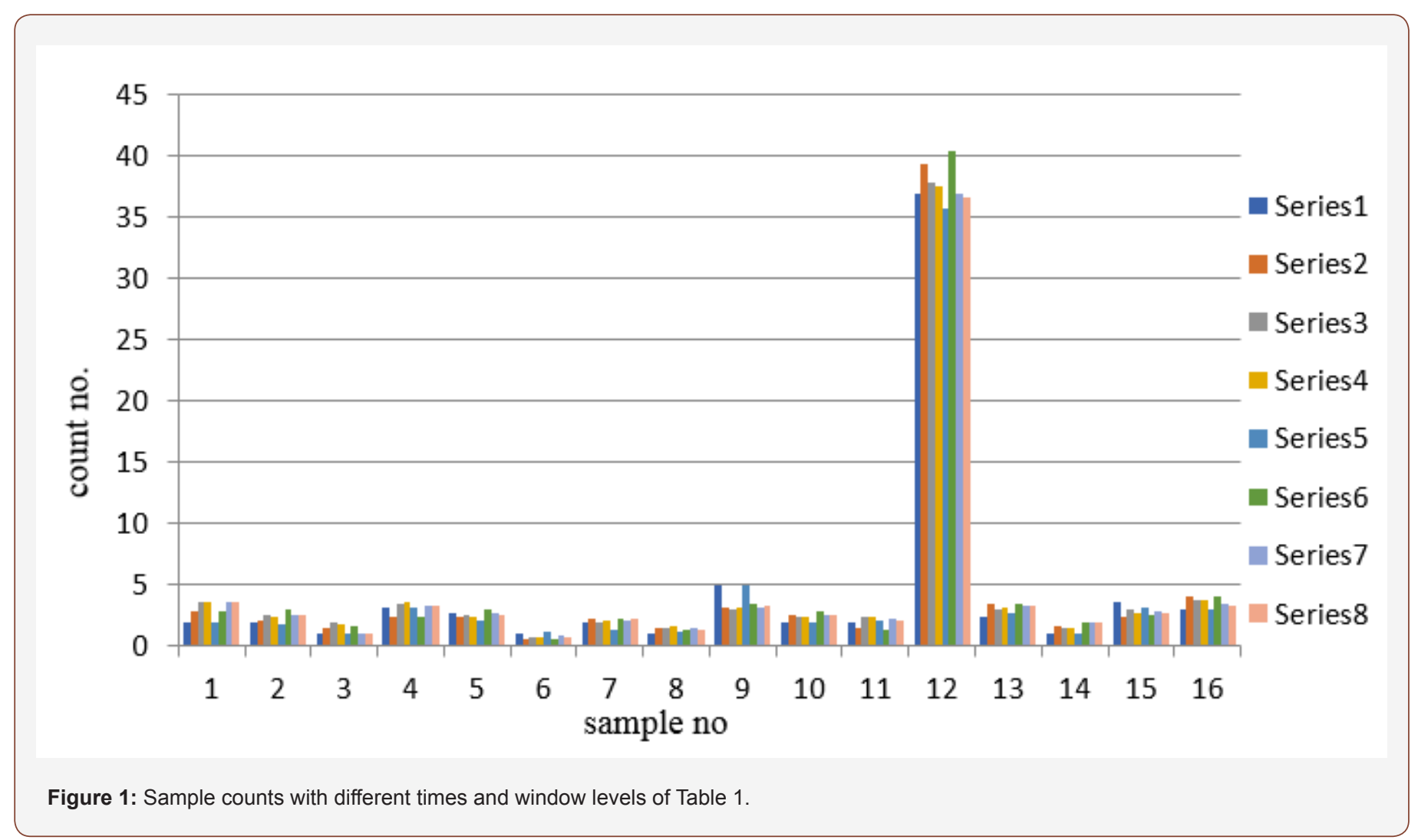




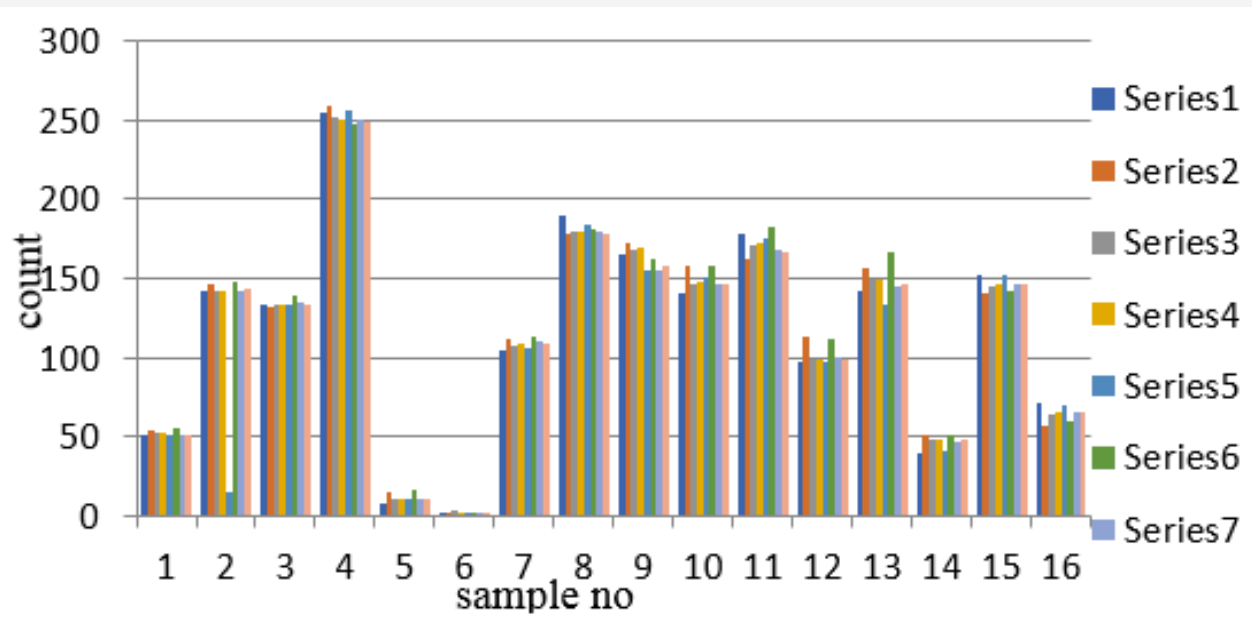

Figure 2: Sample counts with different times and window levels of Table 2.

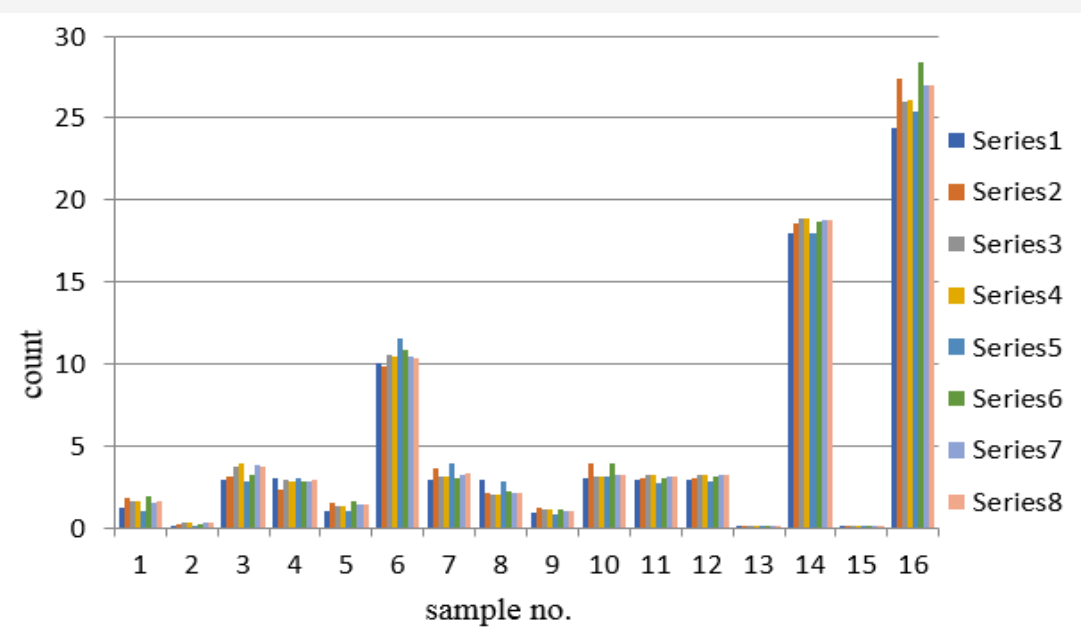

Figure 3: Sample counts with different times and window levels of Table 3.

Table 1: Results of $T_{3}$ hormone different counting time and window level.

\begin{tabular}{|c|c|c|c|c|c|c|c|c|}
\hline \multicolumn{5}{|c|}{$\begin{array}{c}\mathrm{T}_{3} \text { Results of } 16 \text { Samples with } 30,60,90 \text { - And } 120 \text {-Seconds Count with } \\
100 \text {-Channel Window. }\end{array}$} & \multicolumn{4}{|c|}{$\begin{array}{c}\mathrm{T}_{3} \text { Results Of } 16 \text { Samples with } 30,60,90 \text { - and } 120 \text {-Seconds } \\
\text { Count with } 120 \text {-Channel Window. }\end{array}$} \\
\hline $\begin{array}{l}\text { Sample } \\
\text { No }\end{array}$ & $\begin{array}{l}\text { Results of } \\
30 \mathrm{sec}\end{array}$ & $\begin{array}{l}\text { Results of } \\
1.0 \mathrm{~min}\end{array}$ & $\begin{array}{c}\text { Results of } \\
1.50 \mathrm{~min}\end{array}$ & $\begin{array}{l}\text { Results of } \\
2.0 \mathrm{~min}\end{array}$ & $\begin{array}{l}\text { Results of } \\
30 \mathrm{sec}\end{array}$ & $\begin{array}{l}\text { Results of } \\
1.0 \mathrm{~min}\end{array}$ & $\begin{array}{l}\text { Results of } \\
1.50 \mathrm{~min}\end{array}$ & $\begin{array}{l}\text { Results of } \\
2.0 \mathrm{~min}\end{array}$ \\
\hline 1 & 2.01 & 2.86 & 3.69 & 3.58 & 2.01 & 2.86 & 3.69 & 3.58 \\
\hline 2 & 1.98 & 2.15 & 2.5 & 2.46 & 1.78 & 2.94 & 2.58 & 2.5 \\
\hline 3 & 1.03 & 1.53 & 1.89 & 1.78 & 1.01 & 1.63 & 1.09 & 1.01 \\
\hline 4 & 3.19 & 2.38 & 3.48 & 3.56 & 3.23 & 2.35 & 3.25 & 3.36 \\
\hline 5 & 2.73 & 2.34 & 2.54 & 2.47 & 2.03 & 2.98 & 2.64 & 2.58 \\
\hline 6 & 1.02 & 0.52 & 0.68 & 0.75 & 1.12 & 0.61 & 0.88 & 0.69 \\
\hline 7 & 1.89 & 2.2 & 2.01 & 2.12 & 1.39 & 2.3 & 2.14 & 2.24 \\
\hline 8 & 1.02 & 1.52 & 1.48 & 1.59 & 1.12 & 1.42 & 1.54 & 1.41 \\
\hline 9 & 4.91 & 3.22 & 3.08 & 3.1 & 4.98 & 3.42 & 3.18 & 3.27 \\
\hline 10 & 1.97 & 2.63 & 2.48 & 2.35 & 1.89 & 2.91 & 2.55 & 2.49 \\
\hline 11 & 2.01 & 1.49 & 2.45 & 2.39 & 2.11 & 1.39 & 2.25 & 2.15 \\
\hline 12 & 36.87 & 39.37 & 37.89 & 37.56 & 35.77 & 40.37 & 36.89 & 36.54 \\
\hline 13 & 2.46 & 3.43 & 3.01 & 3.12 & 2.68 & 3.44 & 3.24 & 3.32 \\
\hline 14 & 1.04 & 1.71 & 1.56 & 1.49 & 1.01 & 1.91 & 2.01 & 1.98 \\
\hline 15 & 3.56 & 2.44 & 2.98 & 2.76 & 3.12 & 2.53 & 2.88 & 2.65 \\
\hline 16 & 2.99 & 4.06 & 3.71 & 3.84 & 2.96 & 4.1 & 3.5 & 3.38 \\
\hline
\end{tabular}


Table 2: Results $\mathrm{T}_{4}$ for different counting time and window level.

\begin{tabular}{|c|c|c|c|c|c|c|c|c|}
\hline \multicolumn{5}{|c|}{$\begin{array}{l}\mathrm{T}_{4} \text { Results of } 16 \text { Samples with 30, 60, 90- and 120-Seconds Count with } \\
\text { 100-Channel Window. }\end{array}$} & \multicolumn{4}{|c|}{$\begin{array}{c}\mathrm{T}_{4} \text { Results of } 16 \text { Samples with } 30,60,90 \text { - and } 120 \text {-Seconds } \\
\text { Count with } 120 \text {-Channel Window. }\end{array}$} \\
\hline $\begin{array}{l}\text { Sample } \\
\text { No }\end{array}$ & $\begin{array}{l}\text { Results of } \\
30 \mathrm{sec}\end{array}$ & $\begin{array}{l}\text { Results of } \\
1.0 \text { min }\end{array}$ & $\begin{array}{l}\text { Results of } \\
1.50 \mathrm{~min}\end{array}$ & $\begin{array}{l}\text { Results of } \\
2.0 \mathrm{~min}\end{array}$ & $\begin{array}{l}\text { Results of } \\
30 \text { sec }\end{array}$ & $\begin{array}{l}\text { Results of } 1.0 \\
\text { min }\end{array}$ & $\begin{array}{l}\text { Results of } \\
1.50 \mathrm{~min}\end{array}$ & $\begin{array}{l}\text { Results of } \\
2.0 \text { min }\end{array}$ \\
\hline 1 & 50.66 & 54.16 & 52.32 & 52.96 & 50.5 & 55.16 & 51.38 & 51.12 \\
\hline 2 & 141.66 & 146.8 & 141.98 & 142.65 & 14.54 & 147.59 & 142.78 & 143.65 \\
\hline 3 & 134.02 & 132.05 & 133.65 & 133.85 & 134.12 & 139.75 & 134.65 & 134.1 \\
\hline 4 & 255.14 & 258.72 & 251.12 & 250.56 & 256.14 & 247.32 & 250.91 & 249.35 \\
\hline 5 & 8.36 & 15.79 & 10.23 & 10.58 & 10.45 & 16.79 & 11.24 & 11.39 \\
\hline 6 & 2.85 & 1.36 & 2.98 & 2.23 & 2.75 & 1.51 & 2.18 & 2.01 \\
\hline 7 & 105.32 & 111.79 & 107.68 & 108.52 & 106.49 & 112.78 & 109.68 & 109.52 \\
\hline 8 & 189.2 & 178.83 & 179.02 & 179.36 & 183.45 & 180.83 & 179.12 & 178.93 \\
\hline 9 & 165.23 & 171.82 & 168.29 & 168.88 & 155.81 & 161.76 & 155.29 & 157.37 \\
\hline 10 & 140.32 & 157.93 & 146.99 & 147.24 & 150.32 & 157.45 & 145.99 & 146.23 \\
\hline 11 & 178.33 & 162.83 & 170.32 & 171.89 & 175.33 & 182.83 & 167.54 & 166.94 \\
\hline 12 & 96.81 & 112.76 & 99.45 & 98.87 & 97.52 & 111.41 & 99.81 & 99.32 \\
\hline 13 & 142.32 & 156.48 & 148.78 & 149.06 & 132.98 & 166.93 & 145.19 & 146.65 \\
\hline 14 & 39.74 & 51.32 & 48 & 48.35 & 40.55 & 50.98 & 47.14 & 48.89 \\
\hline 15 & 152.32 & 140.41 & 145.46 & 146.64 & 151.93 & 142.54 & 146.46 & 146.64 \\
\hline 16 & 71.44 & 57.48 & 64.22 & 65.21 & 70.61 & 59.73 & 66.04 & 65.49 \\
\hline
\end{tabular}

Table 3: Results TSH for different counting time and window level.

\begin{tabular}{|c|c|c|c|c|c|c|c|c|}
\hline \multicolumn{5}{|c|}{ TSH Results of $\mathbf{1 6}$ Samples with 30, 60, 90- and 120-Seconds Count with } & \multicolumn{3}{|c|}{ TSH Results of 16 Samples with 30, 60, 90- and 120-Seconds } \\
Count with 120-Channel Window.
\end{tabular}

\section{Conclusion}

Nuclear Medicine techniques deal with both diagnostic and therapeutic and academic aspects. Radio Immunoassay (RIA) and Immuno-Radiometric Assay (IRMA) have been playing an important role in estimation of different hormones. It is well known that radio isotopic method for the determination of hormone level is a very popular and an accurate method. It is very inexpensive $(25 \%)$ in comparison to other available methods. It is based on the counting of Radionuclide precipitation after reaction. Generally, very low energy gamma photon (30kev) is used as the tracer and $\mathrm{NaI}(\mathrm{Tl})$ scintillation detector is used. The technology is well established and in recent years due to tremendous development of microelectronics, performance is improved significantly. Scintillation crystal, PMT, preamp, amp, PHA, data transfer capacity are the important factors for accurate measurements. As the technology uses low energy photon, the pulses mix with electrical noise, so signal to noise ratio is important. Although from the study, it is observed that counting time and window level are not changing the level of the result significantly, but the factor may be very important if the system is not highly stable. Quality control (QC) and quality assurance of the 
equipment are very important. If the system parameters satisfy QC test with a higher degree, standard time and window may be used but if the $\mathrm{QC}$, value is poor or medium in that case higher counting time and window should be used.

\section{Acknowledgement}

This research work has been done with the financial support of University Grant Commission, Bangladesh through the Faculty of Engineering, University of Rajshahi. The researchers also acknowledge the supports of Bangladesh Atomic Energy Commission and the Institute of Nuclear Medicine and Allied Sciences (INMAS), BAEC, Rajshahi, Bangladesh

\section{Conflict of Interest}

No conflict of interest.

\section{References}

1. Agarwal's (1985) A Textbook of Biochemistry (physiological chemistry), second edition, Goel Publishing House, Meerut. Pp. 188.

2. Nick Neave (2008) Hormones and Behavior A Physiological Approach, Cambridge University Press.

3. K Sembulingam, Prema Sembulingam (2012) Essential of Medical Physiology, sixth edition, Jaypee Brothers Medical Publishers ltd.
4. Oppenheimer JH (1968) Role of plasma proteins in the binding, distribution and metabolism of the thyroid hormones. New England Journal of Medicine 278: 1153-1162.

5. Mardell R (1978) A strategy for in-vitro tests of thyroid function. Amersham, the Radiochemical Centre, pp. 21.

6. Kuby Immunology, Sixth Edition $6^{\text {th }}$ Edition by Thomas J Kindt (Author), Barbara A Osborne (Author), Richard A Goldsby (Author Lehninger, Biochemistry, second edition, pp. 824-825.

7. Montgomery, Conway, Specter, Biochemistry, A case-oriented Approach, fifth edition, P. 787-801.

8. Calsolaro V, Niccolai F, Pasqualetti G, Calabrese AM, Polini A, et al. (2019) Overt and Subclinical Hypothyroidism in the Elderly: When to Treat? Front Endocrinol (Lausanne). 10: 177.

9. Stephen Nussey and Saffron Whitehead (2001) "Endocrinology an Integrated Approach". Oxford: BIOS Scientific Publishers.

10. Mardell RA (1978) strategy for in-vitro tests of thyroid function. Amersham, the Radiochemical Centre, pp. 21.

11. Prasad JA et al. (1979) Thyroxin and Triiodothyronine. In "Method of Hormone Radioimmunoassay". p. 375.

12. (1982) Ionizing Radiation's, Sources and Biological Effect UNSCEAR 1982 report.

13. Vohra KG (1961) Symposium on Low Energy Nuclear Physics. Bombay.

14. Harley NI, fisenne LDY, Ong et al. (1965) Fission yield and fission product decay, HASL- 164: 256-260. 